\title{
Can thromboembolic risk be associated with erectile dysfunction in atrial fibrillation patients?
}

\author{
Filip M. Szymański, Krzysztof J. Filipiak, Anna E. Płatek, \\ Marcin Kotkowski, Grzegorz Opolski \\ $1^{\text {st }}$ Department of Cardiology, Medical University of Warsaw, Warsaw, Poland
}

\begin{abstract}
Background: Erectile dysfunction (ED) is highly prevalent in patients with diseases of cardiovascular system, including patients with atrial fibrillation $(A F)$. Reasons for this high co-prevalence include endothelial dysfunction, inflammation, oxidative and emotional stress associated with AF. Association of AF-induced prothrombotic state and possible microthrombi in penile arteries with ED remains unclear. The present study aims to assess if probability of $A F$-associated risk of peripheral thromboembolism may be associated with ED in AF patients.

Methods: Probability of thromboembolic complications was assessed with two commonly used risk scores $C H A D S_{2}$ and $\mathrm{CHA}_{2} D S_{2}$-VASc in a group of continuous $A F$ patients. All patients were also asked to fill an IIEF-5 questionnaire designed for screening for ED.

Results: Mean $\mathrm{CHADS}_{2}$ score in the whole study group was $1.1 \pm 1.0$ points and $\mathrm{CHA}_{2} \mathrm{DS}_{2^{-}}$ -VASc was $1.5 \pm 1.4$ points. ED was present in $57.4 \%$ of the 129-person study population. In patients with $E D$, both $C H A D S_{2}(0.9 \pm 1.0$ vs. $1.3 \pm 1.1 ; p=0.03)$ and $C H A_{2} D S_{2}-V A S c$ (1.2 \pm 1.1 vs. $1.8 \pm 1.5 ; p=0.03)$ scores were significantly higher than in the group without dysfunction. After dividing the patients according to age into groups younger than 65 years $v s . \geq 65$ years, observed correlation was no longer significant in the younger group $(p>0.05)$. In patients $\geq 65$ years, in whom the risk scores are routinely used, dysfunction both $\mathrm{CHADS}_{2}$ $(1.1 \pm 0.9$ vs. $2.0 \pm 0.9 ; p=0.02)$ and $C H A_{2} D S_{2}-V A S c(2.3 \pm 1.1$ vs. $3.4 \pm 1.3 ; p=0.04)$ scores were higher in the group with ED.

Conclusions: Erectile dysfunctions in AF patients are associated with elevated cardioembolic risk. We postulate that the diagnosis of ED should be considered an additional marker of prothrombotic state, and may be useful in clinical decision-making, especially in patients $\geq 65$ years old. (Cardiol J 2015; 22, 4: 446-452)
\end{abstract}

Key words: erectile dysfunction, thromboembolic risk, atrial fibrillation

Editorial p. 359

\section{Introduction}

Erectile dysfunction (ED) is one of the most disabling sexual dysfunctions. It is defined as a consistent or recurrent inability to acquire or sustain an erection of sufficient rigidity and duration for sexual intercourse. In a selected population of men of ages ranged from 20 to 75 years, the overall prevalence of ED is estimated to be $16 \%$ but raises up to $37 \%$ in men $70-75$ years of age [1]. These statistics are much higher in patients with a disease of the cardiovascular (CV) system, 
especially associated with impaired vascular function and/or blood flow like arterial hypertension, atherosclerosis-related coronary and peripheral artery disease. Moreover, in patients with CV disease, ED is often associated with increased mortality and morbidity risk [2-5]. It has been recently reported that also patients with atrial fibrillation (AF) are at high risk of ED.

Erectile dysfunction arises as a result of concomitance of several components from genetic and anatomical dysfunctions, through the systemic disease to impact of lifestyle and environment. In many cases, a single cause of ED is not easy to determine, and ED is more of a result of several overlapping conditions [6]. Nevertheless, in CV patients, a significant number of ED cases is associated with alterations of the vascular function, which can be associated with endothelial dysfunction, inflammation, oxidative and emotional stress or sympathetic activation [7-9]. Another factor strongly associated with ED is limitation of the blood flow in penile arteries caused either by obstruction associated with atherosclerosis or by microthrombi [6].

In $\mathrm{AF}$ patients, it was found that most of the previously described risk factors of the vascular dysfunction are elevated [10-12]. AF is also strongly associated with elevated thromboembolic risk. AF patients by definition are at elevated risk of thromboembolic stroke, deep vein thrombosis, and other end organs ischemia, therefore management and prevention of thrombosis-associated vascular events is one of the main treatment goals in $\mathrm{AF}$ patients $[13,14]$. According to current guidelines assessment of thromboembolic risk and decision on therapeutic approach is made basing of risk score, mainly $\mathrm{CHADS}_{2}$ and $\mathrm{CHA}_{2} \mathrm{DS}_{2}$-VASc [14].

Little data is available on the potential link between elevated thromboembolic risk in $\mathrm{AF}$ patients and its impact on ED. Association of AF-induced prothrombotic state and possible microthrombi in penile arteries with ED remains unclear. Present study aims to assess if elevated risk of peripheral thromboembolism assessed by $\mathrm{CHADS}_{2}$ and $\mathrm{CHA}_{2} \mathrm{DS}_{2}$-VASc scores may be associated with ED in $\mathrm{AF}$ patients.

\section{Methods}

\section{Study population}

The study was designed as a prospective cross-sectional cohort study. Data were collected during the period from July, 2013 to July, 2014. The study population consisted of consecutive male patients aged $>18$ and $\leq 70$ years with a primary diagnosis of AF. Study patients were either electively hospitalized with a primary diagnosis of AF, or had a scheduled outpatient visit in one of the University Cardiology Departments participating in the study. $\mathrm{AF}$ was diagnosed based on $\geq 1$ arrhythmia episode recorded in a 24-h electrocardiogram (ECG) Holter monitoring or standard 12-lead ECG in the last 6 months. AF was classified as paroxysmal when it was self-terminating. Persistent AF was defined when an arrhythmia episode either lasted longer than 7 days or required termination by cardioversion, and permanent AF was diagnosed when it was decided not to pursue rhythm control strategy. Due to similar clinical manifestation, persistent and permanent $\mathrm{AF}$ were analyzed as one group.

Patients were excluded from the study if they had: a history of prostatectomy or other procedures associated with a loss of sexual function, current use of phosphodiesterase type 5 (PDE-5) inhibitors, for patients hospitalized due to AF - acute presentation on admission, myocardial infarction, stroke or decompensation of heart failure within 6 months prior to study entry, fatal condition with estimated life expectancy of $\leq 6$ months, general health status described as "frail" or "in poor general health" by the managing physician. Physical examination and medical history taking were performed in all the cases, and patients were assessed in the thromboembolic risk scores and were asked to fill in the ED tool described in detail below. All patients gave a written, informed consent prior to the study entry and the study protocol was approved by the University Ethics Committee.

\section{Erectile dysfunction assessment}

Erectile dysfunction was evaluated using the International Index of Erectile Function (IIEF) score. The IIEF has been described in detail previously. It is a self-administered questionnaire that provides data on ED 98\% sensitivity and 88\% specificity [15]. Patients' responses are based on their experience during the last 4 weeks, and are scored on a 5-point scale, where lower values represent poorer sexual function. Erectile dysfunction was diagnosed when patient scored 25 points or less [16].

\section{Thromboembolic risk assessment}

The $\mathrm{CHADS}_{2}$ and $\mathrm{CHA}_{2} \mathrm{DS}_{2}$-VASc scores are widely used clinical risk scores based only on clinical parameters $[17,18]$. The scores were calculated for all patients included in the study, according to the scheme described below. In the $\mathrm{CHADS}_{2}$ score 
for: history of congestive heart failure -1 point, arterial hypertension -1 point, age $\geq 75$ years -1 point, diabetes -1 point, and for history of stroke or transient ischemic attack (TIA) 1 point. Diagnoses of all the diseases mentioned above were made based on the current diagnosis criteria, either as de novo diagnosis or according to patients' medical records. The $\mathrm{CHA}_{2} \mathrm{DS}_{2}$-VASc scoring was as follows: heart failure -1 point, arterial hypertension -1 point, age $\geq 75$ years -2 points, diabetes -1 point, history of stroke or TIA -2 points, vascular disease (history of myocardial infarction, presence of complex aortic plaque, or peripheral artery disease) -1 point, age 65-74 years -1 point, and female sex -1 point. As the current guidelines recomend assessment of the thromboembolic risk only in patients $>65$ years of age, we performed an additional analysis for two separate groups: patients $\leq 65$ and $>65$ years of age.

\section{Statistical analysis}

Continuous data are presented as mean \pm standard deviation (SD) and were compared using either the Mann-Whitney or Student's $t$-test depending on the normal distribution, tested using the Kolmogorov-Smirnov test. Categorical variables are presented as the number of patients (percentage of the population), and their comparison was made using either the $\chi^{2}$ or Fisher's exact test. A p value of less than 0.05 was considered statistically significant. All analyses were performed using SAS statistical software version 8.02 (SAS Institute, Inc., Cary, NC, USA).

\section{Results}

One hundred and twenty nine patients were enrolled into the study. Mean age of the study population was 57 years. Majority (58.9\%) of patients in the study population had paroxysmal AF. Cardiovascular risk factors were present in many of the patients. Twenty-two point five percent had diabetes mellitus, $60.5 \%$ had arterial hypertension, and $18.6 \%$ were current smokers; dyslipidemia was diagnosed in $46.5 \%$ of patients. It translated into the elevated thromboembolic risk, which was assessed in the described risk scores. Mean $\mathrm{CHADS}_{2}$ score in the whole study group was $1.1 \pm$ \pm 1.0 points and $\mathrm{CHA}_{2} \mathrm{DS}_{2}$-VASc was $1.5 \pm 1.4$ points. Baseline characteristics of the study population are described in Table 1.

Prevalence of the ED in the whole study population was high. Erectile dysfunction was di-
Table 1. Baseline characteristics of the study population.

\begin{tabular}{lc}
\hline Parameter & $\begin{array}{c}\text { Mean } \pm \text { SD } \\
\text { or } \mathbf{n}(\%)\end{array}$ \\
\hline Age [years] & $57.0 \pm 11.8$ \\
Paroxysmal AF & $76(58.9 \%)$ \\
Body mass index $\left[\mathrm{kg} / \mathrm{m}^{2}\right]$ & $29.3 \pm 4.1$ \\
Waist circumference $[\mathrm{cm}]$ & $102.1 \pm 12.6$ \\
Systolic BP $[\mathrm{mm} \mathrm{Hg]}$ & $136.0 \pm 16.8$ \\
Diastolic BP $[\mathrm{mm} \mathrm{Hg}]$ & $83.5 \pm 11.8$ \\
Prior myocardial infarction & $14(10.9 \%)$ \\
Diabetes mellitus & $29(22.5 \%)$ \\
Arterial hypertension & $78(60.5 \%)$ \\
Smoking & $24(18.6 \%)$ \\
Prior stroke & $8(6.2 \%)$ \\
Dyslipidemia & $60(46.5 \%)$ \\
Family history of CVD & $59(45.7 \%)$ \\
\hline
\end{tabular}

SD - standard deviation; AF — atrial fibrillation; BP — blood pressure; CVD - cardiovascular disease

agnosed in 74 (57.4\%) patients. Few factors were significantly different between the groups, and they are described in the Table 2. Patients with ED were older $(60.1 \pm 10.7$ years $)$ than the patients without the dysfunction $(53.0 \pm 12.0$ years, $\mathrm{p}=0.003)$, also waist circumference was higher in patients with the dysfunction $(102.3 \pm 10.4$ vs. $101.7 \pm$ $\pm 15.9 \mathrm{~cm}, \mathrm{p}<0.0001)$. When we analyzed patients according to the history of myocardial infarction, there was a trend towards higher prevalence of history of myocardial infarction in patients $(16.2 \%$ vs. 3.6\%), but it did not reach the level of statistical significance $(\mathrm{p}=0.052)$. In patients with $\mathrm{ED}$, both $\mathrm{CHADS}_{2}(0.9 \pm 1.0$ vs. $1.3 \pm 1.1 ; \mathrm{p}=0.03)$ and $\mathrm{CHA}_{2} \mathrm{DS}_{2}$-VASc $(1.2 \pm 1.1$ vs. $1.8 \pm 1.5 ; \mathrm{p}=0.03)$ scores were significantly higher than in the group without dysfunction (Fig. 1). We observed no differences between the groups with and without ED in terms of prescribed medications, including betablocker, diuretic, angiotensin converting enzyme inhibitors, or statins ( $p>0.05)$.

When we divided patients in the manner described in the guidelines, in the group younger than 65 and $\geq 65$ years of age, we observed additional differences described in detail in Table 3. In patients younger than 65 years, factors different between the groups with and without ED were: age $(55.2 \pm 7.8$ vs. $50.6 \pm 10.9$ years; $\mathrm{p}=0.03)$ and current smoking ( $32.7 \mathrm{vs.} 32.3 \% ; \mathrm{p}=0.05)$. In this group of patients, the observed association between the thromboembolic risk was not significant 
Table 2. Differences between patients with and without erectile dysfunction (ED).

\begin{tabular}{lccc}
\hline Parameter & $\begin{array}{c}\text { Patients without } \\
\text { the ED (n = 55) }\end{array}$ & $\begin{array}{c}\text { Patients with } \\
\text { the ED (n = 74) }\end{array}$ & P \\
\hline Age [years] & $53.0 \pm 12.0$ & $60.1 \pm 10.7$ & $\mathbf{0 . 0 0 3}$ \\
Paroxysmal AF & $37(67.3 \%)$ & $39(52.7 \%)$ & 0.11 \\
Body mass index $\left[\mathrm{kg} / \mathrm{m}^{2}\right]$ & $29.5 \pm 4.4$ & $29.1 \pm 3.8$ & 0.54 \\
Waist circumference $[\mathrm{cm}]$ & $101.7 \pm 15.9$ & $102.3 \pm 10.4$ & $\mathbf{0 . 0 0 0 1}$ \\
Systolic BP [mm Hg] & $134.0 \pm 15.6$ & $137.4 \pm 17.6$ & 0.3 \\
Diastolic BP [mm Hg] & $81.0 \pm 10.6$ & $85.3 \pm 12.3$ & 0.08 \\
Prior myocardial infarction & $2(3.6 \%)$ & $12(16.2 \%)$ & $\mathbf{0 . 0 5 2}$ \\
Diabetes mellitus & $9(16.4 \%)$ & $20(27.0 \%)$ & 0.25 \\
Arterial hypertension & $29(52.7 \%)$ & $49(66.2 \%)$ & 0.21 \\
Smoking & $6(10.9 \%)$ & $18(24.3 \%)$ & 0.09 \\
Prior stroke & $6(10.9 \%)$ & $2(2.7 \%)$ & 0.11 \\
Dyslipidemia & $25(45.5 \%)$ & $35(47.3 \%)$ & 0.85 \\
Family history of CVD & $24(43.6 \%)$ & $35(47.3 \%)$ & 0.89 \\
CHADS & $0.9 \pm 1.0$ & $1.3 \pm 1.1$ & 0.03 \\
CHA $_{2}$ DS $_{2}$-VASc & $1.2 \pm 1.1$ & $1.8 \pm 1.5$ & 0.03 \\
\hline
\end{tabular}

Values are mean \pm standard deviation or $\mathrm{n}(\%)$; $\mathrm{AF}$ - atrial fibrillation; $\mathrm{BP}$ - blood pressure; CVD — cardiovascular disease

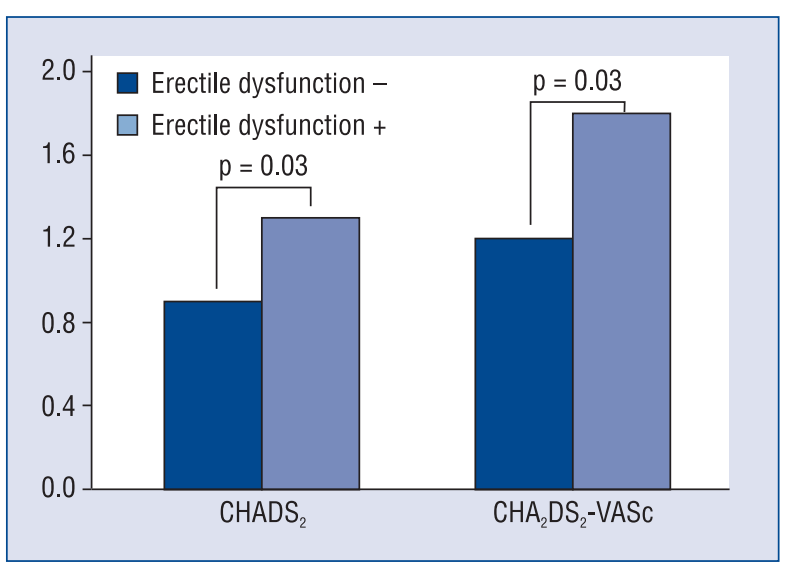

Figure 1. Association between erectile dysfunction and $\mathrm{CHADS}_{2}$ and $\mathrm{CHA}_{2} \mathrm{DS}_{2}$-VASc scores in the study population.

$(1.0 \pm 1.0$ vs. $0.9 \pm 1.0 ; \mathrm{p}=0.43$, and $1.1 \pm 1.1$ vs. $0.9 \pm 1.0 ; \mathrm{p}=0.41)$, respectively for $\mathrm{CHADS}_{2}$ and $\mathrm{CHA}_{2} \mathrm{DS}_{2}$-VASc (Fig. 2A).

In patients $\geq 65$ years, in whom the risk scores are routinely used, the only factor different between the group with and without ED was age $(71.2 \pm 4.9$ vs. $66.5 \pm 1.9$ years; $p=0.003)$ and the thromboembolic risk assessed in the described scores. In patients with ED, both $\mathrm{CHADS}_{2}(1.1 \pm$ \pm 0.9 vs. $2.0 \pm 0.9 ; \mathrm{p}=0.02$ ) and $\mathrm{CHA}_{2} \mathrm{DS}_{2}$-VASc $(2.3 \pm 1.1$ vs. $3.4 \pm 1.3 ; \mathrm{p}=0.04)$ scores were higher in the group with erectile dysfunction (Fig. 2B).

\section{Discussion}

Erectile dysfunction in patients with $\mathrm{CV}$ disease is usually associated with coronary artery disease, cerebrovascular disease or peripheral artery disease. The high prevalence of ED in this group of patients has been extensively described and is associated with atherosclerotic lesions present in the coronary, cerebral, and peripheral, as well as penile arteries. Presence of the dysfunction is also a marker of poorer general condition and prognosis [19-22]. In this case, causes of high co-prevalence of ED with those conditions are well known, and the proposed pathophysiologic mechanism is known in the literature as the artery size hypothesis [23]. According to it, because of the systemic nature of atherosclerosis, all major vascular beds are affected to the same extent. Given the different size of the arteries supplying different vascular beds (i.e. heart and penis) the larger vessel would better tolerate the same amount of plaque compared with a smaller one [23]. Therefore, ED may be an early sign of atherosclerotic disease, and by definition it should be found in majority of coronary artery disease patients.

In the case of AF, the pathophysiologic mechanisms are completely different, and not yet fully understood. As it was reported previously, ED is also common in patients with $\mathrm{AF}$, but not related to atherosclerosis. In our study, ED was present 
Table 3. Differences between patients with and without erectile dysfunction (ED) according to age.

\begin{tabular}{|c|c|c|c|}
\hline Parameter & Patients without the ED & Patients with the ED & $\mathbf{P}$ \\
\hline \multicolumn{4}{|l|}{ Age $<65$ years } \\
\hline Age [years] & $50.6 \pm 10.9$ & $55.2 \pm 7.8$ & 0.03 \\
\hline Paroxysmal AF & $31(68.9 \%)$ & $29(55.8 \%)$ & 0.20 \\
\hline Body mass index $\left[\mathrm{kg} / \mathrm{m}^{2}\right]$ & $29.5 \pm 4.6$ & $29.1 \pm 4.0$ & 0.65 \\
\hline Waist circumference [cm] & $100.6 \pm 16.4$ & $102.6 \pm 9.9$ & 0.62 \\
\hline Systolic BP [mm Hg] & $132.5 \pm 15.6$ & $133.8 \pm 16.9$ & 0.72 \\
\hline Diastolic BP [mm Hg] & $81.4 \pm 11.3$ & $85.8 \pm 13.4$ & 0.17 \\
\hline Prior myocardial infarction & $1(2.2 \%)$ & $4(7.7 \%)$ & 0.45 \\
\hline Diabetes mellitus & $7(15.6 \%)$ & $9(17.3 \%)$ & 0.97 \\
\hline Arterial hypertension & $24(53.3 \%)$ & $30(57.7 \%)$ & 0.78 \\
\hline Smoking & $6(13.3 \%)$ & $17(32.7 \%)$ & 0.05 \\
\hline Prior stroke & $4(8.9 \%)$ & $2(3.8 \%)$ & 0.55 \\
\hline Dyslipidemia & $21(46.7 \%)$ & $25(48.1 \%)$ & 0.90 \\
\hline Family history of CVD & $21(46.7 \%)$ & $24(46.2 \%)$ & 0.96 \\
\hline $\mathrm{CHADS}_{2}$ & $0.9 \pm 1.0$ & $1.0 \pm 1.0$ & 0.43 \\
\hline $\mathrm{CHA}_{2} \mathrm{DS}_{2}-\mathrm{VASc}$ & $0.9 \pm 1.0$ & $1.1 \pm 1.1$ & 0.41 \\
\hline \multicolumn{4}{|l|}{ Age $\geq 65$ years } \\
\hline Age [years] & $66.5 \pm 1.9$ & $71.2 \pm 4.9$ & 0.003 \\
\hline Paroxysmal AF & $6(60.0 \%)$ & $10(45.5 \%)$ & 0.70 \\
\hline Body mass index $\left[\mathrm{kg} / \mathrm{m}^{2}\right]$ & $29.5 \pm 3.8$ & $28.9 \pm 3.6$ & 0.70 \\
\hline Waist circumference $[\mathrm{cm}]$ & $107.1 \pm 10.3$ & $101.7 \pm 10.6$ & 0.21 \\
\hline Systolic BP [mm Hg] & $141.7 \pm 14.3$ & $144.9 \pm 16.9$ & 0.67 \\
\hline Diastolic BP [mm Hg] & $78.9 \pm 6.1$ & $84.3 \pm 10.0$ & 0.19 \\
\hline Prior myocardial infarction & $1(10.0 \%)$ & $8(36.4 \%)$ & 0.33 \\
\hline Diabetes mellitus & $2(20.0 \%)$ & $11(50.0 \%)$ & 0.31 \\
\hline Arterial hypertension & $5(50.0 \%$ & $19(86.4 \%)$ & 0.16 \\
\hline Smoking & $0(0.0 \%)$ & $1(4.5 \%)$ & 0.68 \\
\hline Prior stroke & $2(20.0 \%)$ & $0(0.0 \%)$ & 0.14 \\
\hline Dyslipidemia & $4(40.0 \%)$ & $10(45.5 \%)$ & 0.73 \\
\hline Family history of CVD & $3(30.0 \%)$ & $11(50.0 \%)$ & 0.50 \\
\hline $\mathrm{CHADS}_{2}$ & $1.1 \pm 0.9$ & $2.0 \pm 0.9$ & 0.02 \\
\hline $\mathrm{CHA}_{2} \mathrm{DS}_{2}-\mathrm{VASc}$ & $2.3 \pm 1.1$ & $3.4 \pm 1.3$ & 0.04 \\
\hline
\end{tabular}

Values are mean \pm standard deviation or $\mathrm{n}(\%) ; \mathrm{AF}$ - atrial fibrillation; $\mathrm{BP}$ - blood pressure; CVD — cardiovascular disease

in $57.4 \%$ of patients. Given the relatively young mean age of the study population, it is a lot more than in the general population. Only clinical factors associated with higher prevalence of the dysfunction was older age and higher waist circumference (but not higher body mass index). The history of myocardial infarction was at the edge of the statistical significance, which proves that possibly some contribution of the high prevalence may be attributable to the atherosclerosis. Neverthe- less, in majority of $\mathrm{AF}$ patients there were no obstructive lesions in the coronary arteries [24]. We hypothesize that high co-prevalence of $\mathrm{AF}$ and ED, besides the abovementioned endothelial dysfunction, inflammation, and oxidative stress, may be caused by microthrombi circulating in the blood of AF patients.

$\mathrm{AF}$ predisposes to hypercoagulation. The arrhythmia is associated with changes in the blood flow in the heart chambers, which according to 


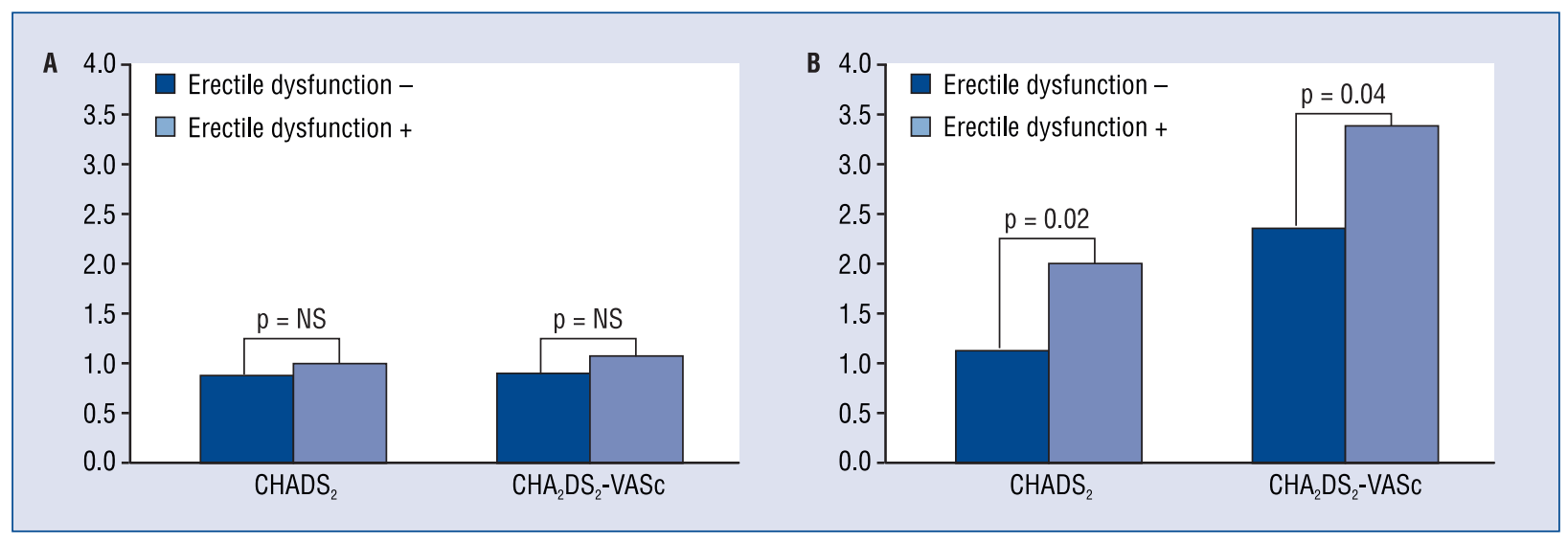

Figure 2. Association between erectile dysfunction and $C H A D S_{2}$ and $\mathrm{CHA}_{2} \mathrm{DS}_{2}-\mathrm{VASc}$ scores according to age; A. Patients $<65$ years of age; B. Patients $\geq 65$ years of age; NS - non significant.

Virchoff's theory promote coagulation. This also translates into altered levels of blood coagulation markers like P-selectin and fibrinogen [25]. The two risk scores most widely used to assess the severity of thrombotic changes and the risk of thrombosis in $\mathrm{AF}$ patients are $\mathrm{CHADS}_{2}$ and $\mathrm{CHA}_{2} \mathrm{DS}_{2}$-VASc scores $[13,14]$. Both scores showed to be predictive not only of thromboembolic stroke risk, but also adverse vascular function, $\mathrm{CV}$ and total death in the whole AF population [26-28]. Moreover, a predictive value of both scores was confirmed also in patients with other conditions, like ischemic heart disease or in patients with comorbidities also influencing thromboembolic risk profile [29-31]. Their elevated values have also been shown to be associated with higher risk of renal damage after invasive procedures [32]. All those findings are caused by elevated thromboembolic risk and increased coagulations. Even if not in all cases the thrombi are large enough to cause visible and/or clinically obvious thrombosis, the obstruction of microvessels and damage to end-organs. Of course, both $\mathrm{CHADS}_{2}$ and $\mathrm{CHA}_{2} \mathrm{DS}_{2}$-VASc scores are not perfect and tend to omit some clinically important variables, with $\mathrm{CHA}_{2} \mathrm{DS}_{2}$-VASc score being more likely to identify patients at lower risk [33]. Nevertheless, in our study, both scores showed to be equally predictive.

The same mechanism may be attributable to the development of ED. Microthrombi forming in the heart and associated with AF may travel with the blood stream to the small-sized penile arteries where they cause occlusion and worsen the sexual function and ability to achieve and maintain an erection, and as it was previously proposed contribute to the development of a clinical syndrome involving $\mathrm{AF}$ and $\mathrm{ED}$ [34]. Of course, the present study only indirectly shows that ED is associated with elevated thromboembolic risk, and other further studies focused mainly on coagulation markers and/or microthrombi visualization techniques are necessary to prove the mentioned hypothesis. Nevertheless, this is the one of the first studies aiming to describe the problem of $\mathrm{ED}$ in $\mathrm{AF}$ patients. Moreover, it is the first to try to provide and explanation for its potential causes. Erectile dysfunction should be perceived as an important problem in AF patients and potentially as a revealing of elevated thromboembolic risk and an additional indication for anticoagulation therapy, especially in low risk patients.

\section{Conclusions}

Erectile dysfunctions are highly prevalent in AF patients and are associated with elevated cardioembolic risk. We postulated that diagnosis of ED should be considered an additional marker of prothrombotic state, and may be useful in clinical decision-making, especially in patients $\geq 65$ years old.

\section{Conflict of interest: None declared}

\section{References}

1. Rosen RC, Fisher WA, Eardley I, Niederberger C, Nadel A, Sand M, Men's Attitudes to Life Events and Sexuality (MALES) Study. The multinational Men's Attitudes to Life Events and Sexuality (MALES) study: I. Prevalence of erectile dysfunction and related 
health concerns in the general population. Curr Med Res Opin, 2004; 20: 607-617.

2. Guo W, Liao C, Zou Y et al. Erectile dysfunction and risk of clinical cardiovascular events: A meta-analysis of seven cohort studies. J Sex Med., 2010; 7: 2805-2816.

3. Puchalski B, Szymański FM, Kowalik R, Filipiak KJ, Opolski G. The prevalence of sexual dysfunction before myocardial infarction in population of Polish men: A retrospective pilot study. Kardiol Pol, 2013; 71: 1168-1173.

4. Burchardt M, Burchardt T, Baer L et al. Hypertension is associated with severe erectile dysfunction. J Urol, 2000; 164: 1188-1191.

5. Meller SM, Stilp E, Walker CN, Mena-Hurtado C. The link between vasculogenic erectile dysfunction, coronary artery disease, and peripheral artery disease: Role of metabolic factors and endovascular therapy. J Invasive Cardiol, 2013; 25: 313-319.

6. Heaton JPW, Adams MA. Causes of erectile dysfunction. Endocrine, 2004; 23: 119-123.

7. Azadzoi KM, Goldstein I. Erectile dysfunction due to atherosclerotic vascular disease: The development of a animal model. J Urol, 1992; 147: 1675-1681.

8. Azadzoi KM, de Teiada IS. Hypercholesterolemia impairs endothelium-dependent relaxation of rabbit corpus cavernosum smooth muscle. J Urol, 1991; 146: 238-240.

9. Solomon H, Man JW, Jackson G. Erectile dysfunction and the cardiovascular patient: Endothelial dysfunction is the common denominator. Heart ,2003; 89: 179-184.

10. Szymanski FM, Filipiak KJ, Karpinski G, Platek AE, Opolski G. Occurrence of poor sleep quality in atrial fibrillation patients according to the EHRA score. Acta Cardiol, 2014; 69: 291-296.

11. Szymański FM, Płatek AE, Karpiński G, Koźluk E, Puchalski B, Filipiak KJ. Obstructive sleep apnoea in patients with atrial fibrillation: Prevalence, determinants and clinical characteristics of patients in Polish population. Kardiol Pol, 2014; 72: 716-724. doi: 10.5603/KP.a2014.0070.

12. Griffiths HR, Lip GY. Biomarkers and risk stratification in atrial fibrillation. Circulation. 2014; 130: 1837-1839. doi: 10.1161/CIRCULATIONAHA.114.012870.

13. Camm AJ, Lip GY, De Caterina R et al.; ESC Committee for Practice Guidelines (CPG). 2012 focused update of the ESC Guidelines for the management of atrial fibrillation: An update of the 2010 ESC Guidelines for the management of atrial fibrillation. Developed with the special contribution of the European Heart Rhythm Association. Eur Heart J, 2012; 33: 2719-2747.

14. Camm AJ, Kirchhof P, Lip GY et al.; European Heart Rhythm Association; European Association for Cardio-Thoracic Surgery, Guidelines for the management of atrial fibrillation: The Task Force for the Management of Atrial Fibrillation of the European Society of Cardiology (ESC). Eur Heart J, 2010; 31: 2369-2429.

15. Rosen RC, Riley A, Wagner G, Osterloh IH, Kirkpatrick J, Mishra A. The International Index of Erectile Function (IIEF): A multidimensional scale for assessment of erectile dysfunction. Urology, 1997; 49: 822-830.

16. Rhoden EL, Telöken C, Sogari PR, Vargas Sout CA. The use of the simplified International Index of Erectile Function (IIEF-5) as a diagnostic tool to study the prevalence of erectile dysfunction. Int J Impot Res, 2002; 14: 245-250.

17. Gage BF, Waterman AD, Shannon W, Boechler M, Rich MW, Radford MJ. Validation of clinical classification schemes for predicting stroke: Results from the National Registry of Atrial Fibrillation. JAMA, 2011; 285: 2864-2870.

18. Lip GY, Nieuwlaat R, Pisters R, Lane DA, Crijns HJ. Refining clinical risk stratification for predicting stroke and thromboembolism in atrial fibrillation using a novel risk factor-based approach: The Euro Heart Survey on atrial fibrillation. Chest, 2010; 137: 263-272.
19. Solomon H, Man JW, Wierzbicki AS, Jackson G. Relation of erectile dysfunction to angiographic artery disease. Am J Cardiol, 2003; 91: 230-231.

20. Kloner R, Mullin S, Shook T et al. Erectile dysfunction in the cardiac patient: How common and should we treat? J Urol, 2003; 170: S46-S50.

21. Kałka D, Domagała Z, Dworak J et al. Association between physical exercise and quality of erection in men with ischaemic heart disease and erectile dysfunction subjected to physical training. Kardiol Pol, 2013; 71: 573-580.

22. Nehra A, Jackson G, Miner M et al. Diagnosis and treatment of erectile dysfunction for reduction of cardiovascular risk. J Urol, 2013; 189: 2031-2038.

23. Montorsi P, Ravagnani PM, Galli S et al. The artery size hypothesis: A macrovascular link between erectile dysfunction and coronary artery disease. Am J Cardiol, 2005; 96: 19M-23M.

24. Nucifora G, Schuijf JD, Tops LF et al. Prevalence of coronary artery disease assessed by multislice computed tomography coronary angiography in patients with paroxysmal or persistent atrial fibrillation. Circ Cardiovasc Imaging, 2009; 2: 100-106.

25. Fu R, Wu S, Wu P, Qiu J. A study of blood soluble P-selectin, fibrinogen, and von Willebrand factor levels in idiopathic and lone atrial fibrillation. Europace, 2011; 13: 31-36.

26. Yap-Hang Chan YH, Yiu KH, Lau KK et al. The CHADS2 and CHA2DS2-VASc scores predict adverse vascular function, ischemic stroke and cardiovascular death in high-risk patients without atrial fibrillation: Role of incorporating PR prolongation. Therosclerosis, 2014; 237: 504-513.

27. Ntaios G, Lip GY, Makaritsis K et al. $\mathrm{CHADS}_{2}, \mathrm{CHA}_{2} \mathrm{~S}_{2} \mathrm{DS}_{2}$-VASc, and long-term stroke outcome in patients without atrial fibrillation. Neurology, 2013; 80: 1009-1017.

28. Hrynkiewicz-Szymanska A, Dluzniewski M, Platek AE et al. Association of the CHADS2 and CHA2DS2-VASc scores with left atrial enlargement: A prospective cohort study of unselected atrial fibrillation patients. J Thromb Thrombolysis, 2015; 40: 240-247. doi: 10.1007/s11239-014-1154-6.

29. Hsu PC, Chiu CA, Chu CY et al. CHADS2 Score and Risk of New-onset Peripheral Arterial Occlusive Disease in Patients without Atrial Fibrillation: A Nationwide Cohort Study in Taiwan. J Atheroscler Thromb, 2015; 20: 490-498. doi: 10.5551/ jat.27284..

30. Lau KK, Chan PH, Yiu KH et al. Roles of the CHADS2 and CHA2DS2-VASc scores in post-myocardial infarction patients: Risk of new occurrence of atrial fibrillation and ischemic stroke. Cardiol J, 2014; 21: 474-483. doi: 10.5603/CJ.a2014.0034.

31. Szymanski FM, Filipiak KJ, Platek AE, Hrynkiewicz-Szymanska A, Karpinski G, Opolski G. Assessment of CHADS2 and CHA2DS2-VASc scores in obstructive sleep apnea patients with atrial fibrillation. Sleep Breath, 2014; 19: 531-537. doi: 10.1007/ s11325-014-1042-5.

32. Kornej J, Hindricks G, Banerjee A et al. Changes in renal function after catheter ablation of atrial fibrillation are associated with CHADS2 and CHA2DS2-VASc scores and arrhythmia recurrences. Heart, 2015; 101: 126-131. doi: 10.1136/ heartjnl-2014-306013.

33. Bednarski J, Cieszewska E, Strzelecki A, Filipiak KJ. Anticoagulant and antiplatelet therapy for stroke prevention in atrial fibrillation patients in the clinical practice of a single district hospital in Poland. Kardiol Pol, 2013; 71: 1260-1265. doi: 10.5603/ KP.a2013.0179.

34. Szymański FM, Puchalski B, Filipiak KJ. Obstructive sleep apnea, atrial fibrillation, and erectile dysfunction: Are they only coexisting conditions or a new clinical syndrome? The concept of the OSAFED syndrome. Pol Arch Med Wewn, 2013; 123 701-707. 